\title{
Association of Psychiatric Disorders in Children and Adolescents with Epilepsy in a Tertiary Care Hospital in Bangladesh
}

\author{
Mohammad Monir Hossain ${ }^{10}$ Shaheen Akhter ${ }^{20}$ \\ M.M. Rahman ${ }^{3}$ Kanij Fatema ${ }^{20}$ \\ M.I.S. Mullik ${ }^{4}$ \\ K.A. Islam ${ }^{2}$ Ayesha Siddika ${ }^{5}$ \\ A.R.M. S.H. Khan ${ }^{2}$ \\ M.Z. Uddin ${ }^{6}$ T. Saad ${ }^{7}$
}
${ }^{1}$ Department of Pediatric Neurology, National Institute of Neuroscience and Hospital, Dhaka, Bangladesh
2 Department of Pediatric Neurology, Institute of Pediatric Neurodisorder and Autism, Bangabandhu Sheikh Mujib Medical University, Dhaka, Bangladesh
${ }^{3}$ Department of Pediatric Neurology, Bangabandhu Sheikh Mujib Medical University, Dhaka, Bangladesh
${ }^{4}$ Department of Psychiatry, Bangabandhu Sheikh Mujib Medical University, Dhaka, Bangladesh
Int J Ep 2021;7:45-51.
Address for correspondence Kanij Fatema, FCPS (Pediatric Neurology and Development), FCPS (Pediatrics), MBBS, Department of Pediatric Neurology, Institute of Pediatric Neurodisorder and Autism, Bangabandhu Sheikh Mujib Medical University, Dhaka, Bangladesh (e-mail: mailmonami@gmail.com).
${ }^{5}$ Department of Community Medicine, Mugda Medical College, Dhaka, Bangladesh
${ }^{6}$ Department of Pediatrics, Jamalpur Sadar Hospital, Jamalpur, Bangladesh
${ }^{7}$ Department of Pediatrics, Dhaka Medical College and Hospital,
Dhaka, Bangladesh

\begin{abstract}
Keywords

- epilepsy

- psychiatric disorders

- children

- adolescents

Background Psychiatric disorders are important aspects of epilepsy and have received increasing attention in the last several years. Although a significant number of children are afflicted with epilepsy with psychiatric comorbidities, the actual burden was not evaluated sufficiently.

Objective To determine the types and frequency of psychiatric disorders in children with epilepsy.

Materials and Methods This hospital-based case-control study was conducted at the outpatient department of a tertiary care center in Dhaka, Bangladesh, from September 2018 to August 2019. In total, 68 epileptic children, ranging from 5 to 17 years of age, were enrolled as cases. A similar number of nonepileptic children of age, sex, and sociodemographic status matched were enrolled as control. Parent, teacher, and selfversion of Bengali Development and Well-Being Assessment (DAWBA) were used to assess the psychiatric disorders, and the diagnosis was assigned as Diagnostic and Statistical Manual (DSM)-V of Mental Disorders.

Results Higher proportion of psychiatric illness were found significantly among the cases $(83.8 \%$ vs. $16.2 \% ; p<0.001)$ and broad categories of disorders, namely, neurodevelopmental ( $30.9 \%$ vs. $1.5 \%, p<0.001)$, emotional ( $48.5 \%$ vs. $7.4 \%, p<0.001$ ) and behavioral disorder ( $19.1 \%$ vs. $7.4 \%, p=0.043$ ) compared with controls. There was a significant relationship between psychiatric disorders with the duration of epilepsy of the respondents $(p=0.032)$.

Conclusions This study result showed the significant association of psychiatric disorders with epilepsy among children and adolescent population. Thus, psychiatric disorders should be properly addressed during treatment of epilepsy.
\end{abstract}

published online

December 2, 2021
DOI https://doi.org/ 10.1055/s-0041-1739399. ISSN 2213-6320. (c) 2021. Indian Epilepsy Society. All rights reserved.

This is an open access article published by Thieme under the terms of the Creative Commons Attribution-NonDerivative-NonCommercial-License, permitting copying and reproduction so long as the original work is given appropriate credit. Contents may not be used for commercial purposes, or adapted, remixed, transformed or built upon. (https://creativecommons.org/ licenses/by-nc-nd/4.0/)

Thieme Medical and Scientific Publishers Pvt. Ltd., A-12, 2nd Floor, Sector 2, Noida-201301 UP, India 


\section{Introduction}

Epilepsy in children is associated with higher rates of behavioral and psychiatric problems. Both externalizing and internalizing disorders occur in children with epilepsy. Uncontrolled seizures, use of antiseizure medications, or both may probably be some of the contributing factors for the association between epilepsy and psychiatric disorders. $^{1-3}$

Psychiatric problems with epilepsy pose a considerable burden on the overall development of children. These disorders are poorly addressed, underrecognized, and undertreated in developing countries like Bangladesh. Recognition of psychiatric disorders at an early stage thus play a pivotal role in ensuring a better quality of life. There are various tools for diagnosis of psychiatric comorbidities in children. The use of standardized interview schedules like Structured Clinical Interview Schedule for Diagnostic and Statistical Manual (DSM)-IV of Mental Disorders Axis 1 disorder (SCID-1) used in previous studies can be time-consuming for routine clinical use. ${ }^{4}$

We did the present study to estimate the proportion of psychiatric disorders and emotional and behavioral problems among children and adolescents with epilepsy in Bangladesh using Development and Well-Being Assessment (DAWBA).

\section{Materials and Methods}

This was a case-control study conducted from September 2018 to August 2019 in the outpatient department of a tertiary health care center of Dhaka, Bangladesh. Inclusion criteria for cases were children from 5 to 17 years who were diagnosed with epilepsy and had no diagnosed premorbid psychiatric disorder.

Another 68 children between 5 to 17 years were taken as control who were age- and sex-matched with the cases, not suffering from epilepsy or any known neurological problem. These subjects were mainly recruited from the outdoor of pediatric department and either came as attendants or came to receive treatment for minor ailments.

Before the commencement of the study, formal ethical approval was taken from the Institutional Review Board (IRB) of the institution. Informed written consent was taken from the parents or caregivers of the study participants. In the case of children aged 11 years or more, informed consent was also taken from them. They were interviewed face to face using a structured questionnaire. Then, the standardized and validated Bengali DAWBA was used for the diagnosis of neurodevelopmental, emotional, and behavioral problems. All parents were interviewed using the parent version of DAWBA. Adolescents of 11 or more years of age were also interviewed using the self-version of DAWBA. Its teacher version was completed by the teachers (school and the home teacher). It was collected from the parents in subsequent visits. Then, one of the authors (M.M.) who is an international rater of DAWBA subsequently reviewed both the verbatim accounts and the answers to structured questions, did the clinical rating, and then assigned psychiatric diagnoses, according to DSM-V criteria. ${ }^{5}$

Detailed history containing the sociodemographic variables and including age, sex, religion, educational status of the child and parents, monthly family income, cultural diversity, and other related information were taken. Detailed history related to epilepsy such as the age of onset of the seizure, duration of illness, type of epilepsy (according to seizure origin), seizure frequency, family history of epilepsy and psychiatric disorders, and antiepileptic therapy at the time of assessment was also recorded. The compliance of drugs was noted. The patients in whom psychiatric comorbidity were identified, psychiatric consultation and pharmacotherapy were given accordingly.

\section{Development and Well-Being Assessment}

It is a well-accepted method consisting of questionnaires, interviews, and rating techniques designed to generate International Classification of Diseases (ICD) 10 and DSM-V psychiatric diagnoses among children and adolescents from 2 to 17 years of age. This instrument was translated into Bengali and standardized and validated by Mullick et al. ${ }^{6}$ The primary purpose of including the DAWBA in a clinical assessment was to make psychiatric diagnoses more accurate. ${ }^{7}$ The interviews were administered by the interviewers who also recorded the verbatim accounts of any reported problems but did not rate them. Experienced clinicians subsequently reviewed both verbatim accounts and answers to the structured questions before assigning diagnoses, according to DSM-V criteria.

The statistical analysis was performed by using the Statistical Package for Social Sciences (SPSS) version 22.0 for Windows. ${ }^{8}$ Categorical variables were expressed as frequency and percentage, and continuous variables were expressed as mean \pm standard deviation (SD). Range of age and median was also recorded. Test of significance was performed by unpaired $t$-test and/or Chi-squared test. The level of significance was defined as a $p$-value of $<0.05$.

\section{Results}

The mean age of cases was $9.49 \pm 3.03$ and controls were $9.69 \pm 3.29$ years. Age ranged from 5 to 16 years. Most of the participants in both groups were aged between 8 to 10 years. Male predominance was observed in both groups. In the case group, $48.5 \%$ were from rural areas, while in the control group, $39.7 \%$ were from rural area. The proportion of the children of case group not attending school were higher than the control group (13.2 vs. $2.9, p<0.05$ ). Fathers of both cases and controls mostly were service holders and mothers were homemakers (-Table $\mathbf{1}$ ).

In the children with epilepsy (CWE), focal seizure was the most common type of seizure (51.5\%), while generalized tonic-clonic seizure (GTCS) was the second common type (44.1\%). Other types of seizure were absence seizure and myoclonic seizure. The duration of epilepsy ranged from 3 to 199 months, with a median of 59 months. The onset of seizure was between 1 and 156 months, with a median of 
Table 1 Sociodemographic characteristics of respondents $(n=136)$

\begin{tabular}{|c|c|c|c|c|}
\hline Characteristics & & $\begin{array}{l}\text { Case } \\
(n=68) \\
\text { No. }(\%)\end{array}$ & $\begin{array}{l}\text { Control } \\
(n=68) \\
\text { No. }(\%)\end{array}$ & p-Value \\
\hline & Mean \pm SD & $9.49 \pm 3.03$ & $9.69 \pm 3.29$ & $0.705^{b}$ \\
\hline \multirow[t]{2}{*}{ Sex } & Male & $44(64.7)$ & 38 (55.9) & \multirow[t]{2}{*}{$0.293^{\mathrm{a}}$} \\
\hline & Female & $24(35.3)$ & $30(44.1)$ & \\
\hline \multirow[t]{3}{*}{ Residence } & Rural & $33(48.5)$ & $27(39.7)$ & \multirow[t]{3}{*}{$0.582^{\mathrm{a}}$} \\
\hline & Urban & $27(39.7)$ & $32(47.1)$ & \\
\hline & Semi urban & $8(11.8)$ & $9(13.2)$ & \\
\hline \multirow[t]{2}{*}{ Enrollment in school } & Goes to school & $59(86.8)$ & $66(97.1)$ & \multirow[t]{2}{*}{$0.028^{\mathrm{a}}$} \\
\hline & Never went to school & $9(13.2)$ & $2(2.9)$ & \\
\hline \multirow[t]{4}{*}{ Occupation of father } & Service holder & $34(50.0)$ & 38 (55.9) & \multirow[t]{4}{*}{$0.705^{\mathrm{a}}$} \\
\hline & Business & $17(25.0)$ & $15(22.1)$ & \\
\hline & Farmer & $7(10.3)$ & $4(5.9)$ & \\
\hline & Abroad & $10(14.7)$ & $10(14.7)$ & \\
\hline \multirow[t]{2}{*}{ Occupation of mother } & Service holder & $16(23.5)$ & $19(27.9)$ & \multirow[t]{2}{*}{$0.556^{\mathrm{a}}$} \\
\hline & Housewife & $52(76.5)$ & $49(72.1)$ & \\
\hline \multirow[t]{4}{*}{ Monthly family income (BDT) } & Up to 10000 & $7(10.3)$ & $2(2.9)$ & \multirow[t]{4}{*}{$0.025^{\mathrm{a}}$} \\
\hline & 10001 to 20000 & $26(38.2)$ & $21(30.9)$ & \\
\hline & 20001 to 50000 & $29(42.6)$ & $27(39.7)$ & \\
\hline & More than 50000 & $6(8.8)$ & $18(26.5)$ & \\
\hline
\end{tabular}

Abbreviations: BDT, Bangladeshi Taka; SD, standard deviation.

Note: Values are expressed as mean \pm SD and within parenthesis percentage (\%) over the column in total.

${ }^{a}$ Chi-squared test $\left(\chi^{2}\right)$ was performed.

${ }^{\mathrm{b}}$ Student $t$-test was performed.

38 months. At the time of enrollment, $36.8 \%$ of epileptic children were seizure-free for the 6 months and $63.2 \%$ were on monotherapy (-Table 2). The most used antiepileptic drug was sodium valproate (42.6\%). Phenobarbital has been used by the CWE for longest median duration of 48 (1-160) months. Only one child got methylprednisolone as immunomodulatory therapy.

Among cases, $83.8 \%$ had psychiatric illness, while among controls, $16.2 \%$ had a psychiatric illness $(p<0.001)$. The types of psychiatric disorders were neurodevelopmental disorders, emotional disorders, and behavioral disorders (30.9\%, 48.5\%, and $19.1 \%$, respectively, in the cases and $1.5 \%, 7.4 \%$, and $7.4 \%$ in the controls).

Psychiatric illness were significantly higher among case group in comparison to control group. Attention deficit hyperactivity disorder (ADHD), oppositional defiant disorder, and conduct disorder were observed significantly in higher proportion in this group $(p<0.05)$. Moreover, autism spectrum disorder, language disorder, and tic disorder including Tourette syndrome were found in $8.8 \%, 2.9 \%$, and $1.5 \%$, respectively, only among the case group. Similarly, generalized anxiety disorder, specific phobia, major depressive disorder, panic disorder, agoraphobia, depressive disorder, and posttraumatic stress disorder were found in $9.0 \%$, $9.0 \%, 5.9 \%, 2.9 \%, 2.9 \%$, and $1.5 \%$, respectively only among the case group (-Table 3). No association of age, sex, education, and monthly family income was observed with the presence of psychiatric illness in the respondents $(p>0.05)$ ( - Table 4).

Among 57 cases with a psychiatric disorder, $40.4 \%$ had a generalized and $54.4 \%$ had a focal epilepsy, while only $5.3 \%$ who were afflicted with epilepsy were categorized as epilepsy syndrome. Cases having more than 6 months of duration of epilepsy had a significantly higher percentage of psychiatric illness than cases having less than 6 months of psychiatric illness (-Table 5 ).

\section{Discussion}

Epilepsy is a neurological condition which affects all groups of ages but peaks in the young individuals and the elderly. ${ }^{9}$ It is associated with increased levels of anxiety, depression, and low self-esteem compared with people without this condition. ${ }^{10}$ This study was designed to assess the extent of psychiatric illness in CWE of Bangladesh.

We found a significant correlation between CWE and psychiatric disorders, where a higher proportion of psychiatric disorders were observed in CWE compared with the healthy controls ( $83.8 \%$ vs. $16.2 \%, p \leq 0.001)$. The psychiatric illnesses are higher in CWE in this study than that of previous studies done by Rabin et al (44\%), Ferdous et al (57.7\%), Dharmadhikari et al (31.2\%) and Rehman et al (50\%). ${ }^{11-14}$ The higher prevalence of psychiatric disorders found in this study 
Table 2 Description of seizure characteristics of children with epilepsy $(n=68)$

\begin{tabular}{|c|c|c|c|c|}
\hline \multicolumn{2}{|l|}{ Characteristics } & \multirow{2}{*}{$\begin{array}{l}\text { Frequency } \\
35\end{array}$} & \multirow{2}{*}{$\begin{array}{l}\text { Percentage (\%) } \\
51.5\end{array}$} & \multirow{2}{*}{$\begin{array}{l}\text { Duration } \\
\text { Median (min-max) }\end{array}$} \\
\hline Types of seizure & Focal & & & \\
\hline & GTCS & 30 & 44.1 & \\
\hline & Absence & 1 & 1.5 & \\
\hline & Myoclonic & 1 & 1.5 & \\
\hline & Other & 1 & 1.5 & \\
\hline \multicolumn{2}{|c|}{ Age of onset of the seizure (in months) } & & & $38.00(1-156)$ \\
\hline \multicolumn{5}{|c|}{ No. of seizures before starting treatment } \\
\hline & Up to 10 & 45 & 66.2 & \\
\hline & 11 to 20 & 14 & 20.6 & \\
\hline & More than 20 & 9 & 13.2 & \\
\hline \multicolumn{5}{|c|}{ Seizure free in the last 6 months } \\
\hline & Yes & 25 & 36.8 & \\
\hline & No & 43 & 63.2 & \\
\hline \multicolumn{5}{|c|}{ Number of antiepileptic drugs taken } \\
\hline & Monotherapy & 43 & 63.2 & \\
\hline & Polytherapy & 23 & 33.8 & \\
\hline & None & 2 & 2.9 & \\
\hline
\end{tabular}

Abbreviation: GTCS, generalized tonic-clonic seizure.

Table 3 Distribution of psychiatric disorders among study groups $(n=136)$

\begin{tabular}{|c|c|c|c|c|}
\hline & & $\begin{array}{l}\text { Case } \\
(n=68) \\
\text { No. (\%) }\end{array}$ & $\begin{array}{l}\text { Control } \\
(n=68) \\
\text { No. (\%) }\end{array}$ & $p$-Value \\
\hline \multicolumn{4}{|l|}{ Psychiatric disorders } & $<0.001$ \\
\hline & Present & $57(83.82 \%)$ & $11(16.18 \%)$ & \\
\hline & Absent & $11(16.18 \% \%$ & $57(83.82 \%)$ & \\
\hline \multicolumn{5}{|l|}{ Category of psychiatric disorder } \\
\hline & Neurodevelopmental disorders ${ }^{a}$ & $21(30.9 \%)$ & $1(1.5 \%)$ & $<0.001$ \\
\hline & Emotional disorder $^{a}$ & $33(48.5 \%)$ & $5(7.4 \%)$ & $<0.001$ \\
\hline & Behavioral disorders $^{a}$ & $13(19.1 \%)$ & $5(7.4 \%)$ & 0.043 \\
\hline \multicolumn{5}{|c|}{ The specific type of psychiatric disorder } \\
\hline Neurodevelopmental disorders & ADHD & $14(20.6 \%)$ & $1(1.5 \%)$ & $<0.001$ \\
\hline \multirow[t]{4}{*}{ Emotional disorder } & Separation anxiety disorder & $3(4.4 \%)$ & $2(2.9 \%)$ & 0.649 \\
\hline & Other anxiety disorder & $5(7.4 \%)$ & $1(1.5 \%)$ & 0.095 \\
\hline & Social phobia & $5(7.4 \%)$ & $1(1.5 \%)$ & 0.095 \\
\hline & Obsessive compulsive disorder & $2(2.9 \%)$ & $3(4.4 \%)$ & 0.649 \\
\hline Behavioral disorders & Oppositional defiant disorder/conduct disorder & $12(17.6 \%)$ & $4(5.9 \%)$ & 0.033 \\
\hline
\end{tabular}

Abbreviation: ADHD, attention deficit hyperactivity disorder.

a Multiple responses considered.

Note: Values are expressed within the parenthesis percentage (\%) over the column in total. $p$-Value was determined by Chi-squared test $\left(\mathrm{X}^{2}\right)$.

could be due to the use of the diagnostic tool, which encompassed all categories of psychiatric disorders that included neurodevelopmental, emotional, behavioral, and somatic disorders. ${ }^{15}$
The presumed mechanisms of association of epilepsy and psychiatric disorders is still unclear. However, there are several hypotheses including insult during early brain development, ictal neurophysiologic effects, inhibition, or hypometabolism 
Table 4 Association of sociodemographic background with psychiatric disorders in children with epilepsy $(n=68)$

\begin{tabular}{|c|c|c|c|}
\hline \multirow{2}{*}{ Factors } & \multicolumn{3}{|c|}{ Psychiatric illness } \\
\hline & $\begin{array}{l}\text { Present } \\
(n=57) \\
\text { No }(\%)\end{array}$ & $\begin{array}{l}\text { Absent } \\
(n=11) \\
\text { No }(\%)\end{array}$ & p-Value \\
\hline \multicolumn{4}{|c|}{ Age of the respondents (years) } \\
\hline $5-10$ & $37(64.9 \%)$ & $9(81.8 \%)$ & 0.272 \\
\hline $11-16$ & $20(35.1 \%)$ & $2(18.2 \%)$ & \\
\hline \multicolumn{4}{|l|}{ Sex of respondents } \\
\hline Male & $39(68.4 \%)$ & $5(45.5 \%)$ & 0.144 \\
\hline Female & $18(31.6 \%)$ & $6(54.5 \%)$ & \\
\hline \multicolumn{4}{|c|}{ The education level of fathers } \\
\hline Below secondary & $15(26.3 \%)$ & $6(54.5 \%)$ & 0.258 \\
\hline Secondary & $17(29.8 \%)$ & $3(27.3 \%)$ & \\
\hline Higher secondary & $10(17.5 \%)$ & $2(18.2 \%)$ & \\
\hline Graduation & $9(15.8 \%)$ & 0 & \\
\hline Postgraduation & $6(10.5 \%)$ & 0 & \\
\hline \multicolumn{4}{|c|}{ The education level of mothers } \\
\hline Below secondary & $21(36.8 \%)$ & $6(54.5 \%)$ & 0.717 \\
\hline Secondary & $14(24.6 \%)$ & $3(27.3 \%)$ & \\
\hline Higher secondary & $10(17.5 \%)$ & $1(9.1 \%)$ & \\
\hline Graduation & $8(14.0 \%)$ & $1(9.1 \%)$ & \\
\hline Postgraduation & $4(7.0 \%)$ & 0 & \\
\hline \multicolumn{4}{|c|}{ Monthly income of the family (BDT) } \\
\hline Up to 10000 & $5(8.8 \%)$ & $2(18.2 \%)$ & 0.309 \\
\hline 10001 to 20000 & $20(35.1 \%)$ & $6(54.5 \%)$ & \\
\hline 20001 to 50000 & $26(45.6 \%)$ & $3(27.3 \%)$ & \\
\hline$>50000$ & $6(10.0 \%)$ & 0 & \\
\hline
\end{tabular}

Abbreviation: BDT, Bangladeshi taka.

Note: Values are expressed within the parenthesis percentage (\%) over the column in total. $p$-Value was determined by Chi-squared test $\left(x^{2}\right)$.

surrounding the epileptic focus and secondary epileptogenesis. Parallel changes of serotonin, norepinephrine, dopamine, and gamma-aminobutyric acid (GABA) may be operant in the pathophysiology of depressive disorders and epilepsy. GABA is the most important inhibitory transmitter in the central nervous system (CNS). Evidence suggests that the abnormal functioning of GABA receptors could be of great importance in the pathophysiology of epilepsy and anxiety disorders. ${ }^{15}$ Besides, behavioral disturbances associated with epilepsy may be related to the seizure discharge itself. Multiple neurotransmitters are involved in this circuit, including substance $P$ and GABA. Furthermore, restricted life due to fear of seizure recurrence, bullying, and superstation may also play a role in the development of the psychiatric disorder. ${ }^{16}$

The most common broad category of disorders were emotional disorders (48.5\%), followed by neurodevelopmental disorders (30.9\%) and behavioral disorders (19.1\%). These
Table 5 Association of the duration of illness (epilepsy) with psychiatric disorders $(n=68)$

\begin{tabular}{|c|c|c|c|}
\hline & \multicolumn{3}{|c|}{ Psychiatric illness } \\
\hline & $\begin{array}{l}\text { Present } \\
(n=57) \\
\text { No (\%) }\end{array}$ & $\begin{array}{l}\text { Absent } \\
(n=11) \\
\text { No (\%) }\end{array}$ & $p$-Value \\
\hline \multicolumn{4}{|l|}{ Type of epilepsy } \\
\hline Generalized epilepsy & $23(40.4 \%)$ & 7 (63.6\%) & 1.00 \\
\hline Focal epilepsy & 31 (54.4\%) & $4(36.4 \%)$ & \\
\hline Epilepsy syndrome & $3(5.3 \%)$ & 0 & \\
\hline \multicolumn{4}{|l|}{ Duration of illness } \\
\hline$\leq 6$ months & $17(29.8 \%)$ & $7(63.6 \%)$ & 0.032 \\
\hline$>6$ months & $40(70.2 \%)$ & $4(36.4 \%)$ & \\
\hline
\end{tabular}

Note: Values are expressed within the parenthesis percentage (\%) over the column in total. $p$-Value was determined by Chi-squared test $\left(\mathrm{X}^{2}\right)$.

categories were significantly higher among CWE compared with controls. Rabin et al found 90.9\% emotional and 9.1\% behavioral disorders among CWE with no significant difference. Furthermore, ADHD/hyperkinesis was the most frequent psychiatric disorder (case-20.6\% vs. control $-1.5 \%, p \leq 0.001$ ) in our study. The similar higher proportion of ADHD/hyperkinesis (31.5\%) in CWE compared with $6.4 \%$ in controls $(p \leq 0.001)$ was found by Hermann et al. ${ }^{17}$ Jones et al found psychiatric disorders in $26.4 \%$ of CWE compared with $10 \%$ in nonepileptic children, which is comparable to our findings. ${ }^{18}$

In this study, no significant association was noted between the sociodemographic profile and psychiatric disorders of CWE. This conforms to the review of Jones et al that the child's age, sex, and socioeconomic status have not been consistently associated with psychopathology in CWE. ${ }^{18}$ However, prolonged duration of epilepsy had a significant relation ( $p=0.032)$ with the development of psychiatric illness. Several other studies also found that prolonged duration of epilepsy was independently associated with worse psychiatric outcomes, although the mechanism is still unclear. ${ }^{19}$

In our study, the average age of CWE was $9.49 \pm 3.03$ years, and the majority belonged to the age group 8 to 10 years (39.7\%). A study conducted by Ferdous et al included children aged between 5 to 16 years and noted that majority CWE belonged to the age group 5 to 10 years $(80.77 \%){ }^{12}$ We also found male predominance (64\%) in this study, which corroborates the findings of the previous studies conducted in the same region. ${ }^{12,20,21}$ However, prevalence studies from other countries showed inconsistent findings with male preponderance, ${ }^{22-24}$ while others did not find persistent sex differences in the incidence of epilepsy. ${ }^{25}$ Sex differences in some epilepsy syndrome are well-documented, but the neurobiology behind this difference is still unclear. ${ }^{26}$

Although education and occupation of parents did not influence epilepsy in children in this study, yet the monthly family income of CWE was significantly lower than that of controls. Ferdous et al found that the majority of CWE came from lower socioeconomic conditions. ${ }^{12}$ This finding 
corresponds with findings from other countries. ${ }^{13,27}$ As most of the studies were conducted in government-run tertiary care hospitals, where people from lower economic class generally take treatment due to low cost, this finding might not represent the situation in the wider community. ${ }^{28}$

In summary, this study explored the proportion of psychiatric disorders among children and adolescents in Bangladesh with epilepsy. However, the present study has some limitations, like it is a single-center cross-sectional study with small sample size. Besides, whether the psychiatric disorders were due to epilepsy itself or was there the influence of antiepileptic drugs on top of epilepsy could not be delineated. Therefore, further study with a large sample size needs to be conducted.

\section{Conclusion}

This study established a significant association of psychiatric disorders with epilepsy among children and adolescents. Thus, psychiatric evaluation should be an integral part of epilepsy management. Furthermore, psychiatric-pediatric liaison system should address the overall treatment of psychiatric illnesses in children with epilepsy.

\section{Funding}

This study was funded by Ministry of Science and Technology, Government of the People's Republic of Bangladesh.

\section{Conflict of Interest}

K.A.I. reports grants from Ministry of Science and Technology, Government of the People's Republic of Bangladesh, while the study was being conducted. A.S. reports grants from Ministry of Science and Technology, Government of the People's Republic of Bangladesh, while the study was being conducted. ARM.SH.K. reports grants from Ministry of Science and Technology, Government of the People's Republic of Bangladesh, while the study was being conducted. T.S. reports grants from Ministry of Science and Technology, Government of the People's Republic of Bangladesh, while the study was being conducted. MZ.U. reports grants from Ministry of Science and Technology, Government of the People's Republic of Bangladesh, while the study was being conducted. K.F. reports grants from Ministry of Science and Technology, Government of the People's Republic of Bangladesh, while the study was being conducted. MM.H. reports grants from Ministry of Science and Technology, Government of the People's Republic of Bangladesh, while the study was being conducted. MM.R. reports grants from Ministry of Science and Technology, Government of the People's Republic of Bangladesh, while the study was being conducted. S.A. reports grants from Ministry of Science and Technology, Government of the People's Republic of Bangladesh, while the study was being conducted. MIS. M. reports grants from Ministry of Science and Technology, Government of the People's Republic of Bangladesh, while the study was being conducted.

\section{References}

1 Gatta M, Raffagnato A, Mannarini S, et al. Pediatric epilepsy and psychiatric comorbidity: preliminary observational data from a prospective study. Minerva Pediatr 2018;70(06):501-512

2 Oh A, Thurman DJ, Kim H. Comorbidities and risk factors associated with newly diagnosed epilepsy in the U.S. pediatric population. Epilepsy Behav 2017;75:230-236

3 Jones JE, Siddarth P, Almane D, Gurbani S, Hermann BP, Caplan R. Identification of risk for severe psychiatric comorbidity in pediatric epilepsy. Epilepsia 2016;57(11):1817-1825

4 Caplan R, Siddarth P, Stahl L, et al. Childhood absence epilepsy: behavioral, cognitive, and linguistic comorbidities. Epilepsia 2008;49(11):1838-1846

5 American Psychiatric Association: Diagnostic and Statistical Manual of Mental Disorders, Fifth Edition. Arlington, VA, American Psychiatric Association 2013

6 Mullick MSI, Goodman R. The prevalence of psychiatric disorders among 5-10 year olds in rural, urban and slum areas in Bangladesh: an exploratory study. Soc Psychiatry Psychiatr Epidemiol 2005;40(08):663-671

7 Aebi M, Kuhn C, Metzke CW, Stringaris A, Goodman R, Steinhausen HC. The use of the development and well-being assessment (DAWBA) in clinical practice: a randomized trial. Eur Child Adolesc Psychiatry 2012;21(10):559-567

8 Corp IBM. IBM SPSS Statistics for Windows. Armonk, NY: IBM Corp.; 2013

9 Beghi E, Giussani G. Aging and the epidemiology of epilepsy. Neuroepidemiology 2018;51(3-4):216-223

10 de Boer HM, Mula M, Sander JW. The global burden and stigma of epilepsy. Epilepsy Behav 2008;12(04):540-546

11 Rabin F, Si M, Js N, et al. Emotional and behavioral disorders in children with epilepsy. Mymensingh Med J 2013;22(02): 313-319

12 Ferdous F, Alam MF, Maruf MM, et al. Psychiatric morbidity in children with epilepsy. Bangladesh J Psychiatry. 2016;30(01):7-9

13 Dharmadhikari AS, Sinha VK, Municipal NC, Hospital G. Psychiatric comorbidity in children with epilepsy: a cross-sectional 5 years rural prevalence study. J Neurosci Rural Pract 2017;8(02):179-184

14 Rehman S, Kalita KK, Baruah A. A hospital based cross sectional study on comorbid psychiatric problems in persons with epilepsy from north eastern part of India. Int J Epilep 2017;4(01):31-35

15 Ahmed HU, Alam MT, Hossain T, Rabbani MG, Chowdhury MWA. Child psychiatry services in Bangladesh: issues and concerns. Eur Psychiatry 2015;30:696

16 Graybiel AM, Canales JJ. The neurobiology of repetitive behaviors: clues to the neurobiology of Tourette syndrome. Adv Neurol 2001; 85:123-131

17 Hermann B, Jones J, Dabbs K, et al. The frequency, complications and aetiology of ADHD in new onset paediatric epilepsy. Brain 2007;130(Pt 12):3135-3148

18 Jones JE, Austin JK, Caplan R, Dunn D, Plioplys S, Salpekar JA. Psychiatric disorders in children and adolescents who have epilepsy. Pediatr Rev 2008;29(02):e9-e14

19 Sculier C, Gaínza-Lein M, Sánchez Fernández I, Loddenkemper T. Long-term outcomes of status epilepticus: a critical assessment. Epilepsia 2018;59(Suppl 2):155-169

20 Banu SH, Khan NZ, Hossain M, et al. Profile of childhood epilepsy in Bangladesh. Dev Med Child Neurol 2003;45(07):477-482

21 Ahmed S, Alam ST, Rahman MM, Akhter S. Clinical profile of early childhood epilepsy: a cross sectional study in a tertiary care hospital. Mymensingh Med J 2016;25(01):96-101

22 Chaudhary N, Gupta MM, Shrestha S, et al. Clinicodemographic profile of children with seizures in a tertiary care hospital: a crosssectional observational study. Neurol Res Int 2017;2017:1524548

23 Eyong KI, Ekanem EE, Asindi AA, Chimaeze T. Clinical profile of childhood epilepsy in Nigerian children seen in a tertiary hospital. Int J Contemp Pediatrics 2017;4(04):1138-1141 
24 Murphy CC, Trevathan E, Yeargin-Allsopp M. Prevalence of epilepsy and epileptic seizures in 10-year-old children: results from the Metropolitan Atlanta Developmental Disabilities Study. Epilepsia 1995;36(09):866-872

25 Kishk N, Mourad H, Ibrahim S, Shamloul R, Al-azazi A, Shalaby N. Sex differences among epileptic patients: a comparison of epilepsy and its impacts on demographic features, clinical characteristics, and management patterns in a tertiary care hospital in Egypt. Egypt J Neurol Psychiat Neurosurg 2019;403 (Suppl):43-44

26 Scharfman HE, MacLusky NJ. Sex differences in the neurobiology of epilepsy: a preclinical perspective. Neurobiol Dis 2014;72(PtB):180-192

27 Khreisat WH. Childhood Focal Epilepsies. Egypt J Hosp Med 2011; 43(April):134-144

28 Allers K, Essue BM, Hackett ML, et al. The economic impact of epilepsy: a systematic review. BMC Neurol 2015;15:245 